Old Dominion University

ODU Digital Commons

\title{
A Framework to Support Interdisciplinary Engagement with Learning Analytics
}

Stephanie J. Blackmon

College of William \& Mary, sjblackmon@wm.edu

Robert L. Moore

Old Dominion University, robmoorephd@gmail.com

Follow this and additional works at: https://digitalcommons.odu.edu/stemps_fac_pubs

Part of the Educational Technology Commons, and the Higher Education Commons

\section{Original Publication Citation}

Blackmon, S. J., \& Moore, R. L. (2020). A framework to support interdisciplinary engagement with learning analytics. In D. Ifenthaler \& D. Gibson (Eds.), Adoption of Data Analytics in Higher Education Learning and Teaching (pp. 39-52). Springer. https://doi.org/https://doi.org/10.1007/978-3-030-47392-1_3

This Book Chapter is brought to you for free and open access by the STEM Education \& Professional Studies at ODU Digital Commons. It has been accepted for inclusion in STEMPS Faculty Publications by an authorized administrator of ODU Digital Commons. For more information, please contact digitalcommons@odu.edu. 


\title{
Chapter 3
}

\section{A Framework to Support Interdisciplinary Engagement with Learning Analytics}

\author{
Stephanie J. Blackmon and Robert L. Moore
}

\subsection{Introduction}

Learning analytics, first introduced circa 2011, has become an emerging field at institutions around the world (Ferguson, Clow, Griffiths, \& Brasher, 2019). The emergence of learning analytics can be linked to the digitization of student records from activity within the learning management system (LMS) to efforts to identify patterns for retention and enrollment management - and has only served to make digital data an invaluable commodity for higher education institutions (Daniel, 2015; de Freitas et al., 2015; Prinsloo \& Slade, 2018). Thus, it is no surprise that the value of data has increased for higher education and has become an essential component in efforts to improve student recruitment and retention as well as identify students who need additional support in their educational pursuits (Asif, Merceron, Ali, \& Haider, 2017; de Freitas et al., 2015). The role of data can be looked at from either the administrative or the instructional side (Picciano, 2012; Shum, 2012). A term frequently used, big data, has been defined by Picciano (2012) as encompassing both the information and systems used to store the digital data as well as the specific transactions found within this data. Yang (2013) further explains that while data may be in the term "big data," the term itself is referring more to how the data is being used and the technologies used to process these data points. While there is still debate about the most effective and ethical way to make use of this student data, there is no dispute that the role of data is an important conversation within institutions of higher education. The need to determine who has access to data, what the data should be used for, and what role students should have in the decision-making

\author{
S. J. Blackmon ( $\square)$ \\ William \& Mary, Williamsburg, VA, USA \\ e-mail: sjblackmon@wm.edu \\ R. L. Moore \\ Old Dominion University, Norfolk, VA, USA
}

(C) Springer Nature Switzerland AG 2020

D. Ifenthaler, D. Gibson (eds.), Adoption of Data Analytics in Higher Education

Learning and Teaching, Advances in Analytics for Learning and Teaching,

https://doi.org/10.1007/978-3-030-47392-1_3 
process around their data are all important considerations for higher education institutions. Thus, we focus our chapter on a discussion of the role this analytics data can play in fostering an interdisciplinary approach to student support.

\subsubsection{What We Mean by Interdisciplinary}

In Rhoten and Pfirman's (2007) article on women in interdisciplinary science, they combine several works to develop their working definition of interdisciplinary as "the integration or synthesis of two or more disparate disciplines, bodies of knowledge, or modes of thinking to produce a meaning, explanation, or product that is more extensive and powerful than its constituent parts" (p. 58). For the purposes of our chapter, we will employ Rhoten and Pfirman's (2007) definition of interdisciplinary. Not only can learning analytics be used across disparate disciplines, but also in disparate ways. It is our assertion that leveraging benefits and mitigating challenges of learning analytics can best be done when institutions adopt a collaborative approach to the implementation of analytics broadly: "integrate" the perspectives, "bodies of knowledge, or modes of thinking" of various disciplines and departments across the institution in order to achieve a more inclusive application of analytics for the overall benefit of students. Therefore, when we refer to interdisciplinarity throughout this chapter, we do so with the aforementioned assertion in mind.

\subsubsection{Big Data and Learning Analytics}

Big data is the driving force of learning. analytics. Learning analytics describes the process of not only collecting these data points but also analyzing and utilizing the data to inform decisions to improve and support student learning and success in educational contexts (Corrin et al., 2019; Ferguson et al., 2019). This type of distillation of the various data points into individualized student outcomes and impacts is one reason that learning analytics is an emerging field of study (de Freitas et al., 2015). Scheffel, Tsai, Gašević, and Drachsler (2019) point out that despite the increased conversations regarding the use of learning analytics in higher education, institutions are in the early stages of truly understanding how to make use of this student data. Learning analytics does not always need to be about remediation or rescuing students. One of the unique features, and attractions of, learning analytics is that there is tremendous flexibility in how it can be used. The challenge, however, is determining what should be used and how it should be used.

Shum (2012) identifies three levels - macro, meso, and micro - for understanding how learning analytics is used within higher education institutions. The overall view of learning analytics would be considered the macro-level. It is at this level that institutions would leverage the data to establish cross-institutional data points. 
An example might be a university system looking at graduation rates in a specific major to ensure student success. Another example at the macro-level would be using data to identify patterns in student behaviors across their entire educational experience, which can be used to impart the insights necessary to provide remediation to students who are experiencing academic challenges (Daniel, 2015). The next level would be the meso-level. At this level, the data is looked at within the institution or a program. A common example here would be enrollment management plans (Voithofer \& Ham, 2018). These are plans that look at past patterns of student enrollment in specific courses, and this data is used to develop predictive models that determine how resources are allocated at the program or department level. The third and final level is the micro-level. At this level, the data is being directly delivered to the students and instructors, often in the form of a dashboard, report, or tool (Shum, 2012). An example for teachers could be a log report from a learning management system (LMS) that tracks what specific course pages or resources are being used by the students. For students, they may have a dashboard that tracks their progress in a specific course or their overall program of study. These dashboards and reports allow students to get more real-time feedback and have more control over their own learning paths (Pardo \& Siemens, 2014; Roberts, Howell, Seaman, \& Gibson, 2016).

While learning analytics has applications across a number of areas, we focus our attention on higher education institutions. As technology has become more and more integrated into business operations at universities, we are seeing a marked increase in the amount of student data that is being collected (and potentially available for analysis) (Asif et al., 2017; Daniel, 2015; Picciano, 2012; Roberts et al., 2016). One of the primary ways that student data is being collected is using learning management systems, such as Blackboard, Sakai, and Moodle. These LMSs offer new ways to capture the activities and learning behaviors of students, such as tracking which resources were accessed and how long students stayed within certain content areas (Moore, 2019).

Just as the use of learning analytics varies between instructors, so too does the use of the LMS. For some instructors, the LMS is simply used to distribute the syllabus, and for other instructors, the LMS is used to manage student interactions in the course from the submission of assignments to discussion forum activities to the calculation of final grades (Moore, 2016). But even when a learning management system offers the potential of rich student data, access to the information may be on an opt-in basis at the university level, leaving lecturers/instructors who may want access to that information with little to no recourse if their institutions do not opt in for learning analytics data. For institutions that do opt in to access learning analytics data, the use of that data may be very individualized from course to course and miss important opportunities to connect data across courses for students' overall success.

This chapter will provide concrete areas as a framework to support the interdisciplinary application of learning analytics data, with considerations related to access and implications of learning analytics use. 


\subsection{Learning Analytics in Higher Education}

The following section discusses the use of learning analytics in higher education administration and in higher education classrooms, and the subsequent section will combine these two areas in order to present an interdisciplinary approach to learning analytics.

\subsubsection{Organizational Drivers}

Analytics use in higher education administration is often discussed in terms of big data that encompasses classroom data as well as data from campus card access and students' usernames for other online services a campus may provide (Aguilar, 2018; Long \& Siemens, 2011; Shorfuzzaman, Hossain, Nazir, Muhammad, \& Alamri, 2019; Wintrup, 2017). The term "big data" has become one of the educational buzzwords that encapsulates many meanings. For the purposes of this chapter, we will use the definition of big data that looks at the technologies that are used to process and analyze the voluminous amount of data collected and stored by institutions of higher education (Daniel, 2015; Picciano, 2012; Yang, 2013). Using the level definitions from Shum (2012), the administrative level would be using macro- or mesolevel types of data. Common examples of micro-level approaches include the development of predictive tools and models that allow for tracking students and imposing early interventions for students who are struggling (Daniel, 2015). Several researchers have pointed out that learning analytics is often used for information on students' progress and overall retention (Bronnimann, West, Huijser, \& Heath, 2018; de Freitas et al., 2015; Gray \& Perkins, 2019; Villano, Harrison, Lynch, \& Chen, 2018). For example, Lonn, McKay, and Teasley (2017) discussed a universitywide analytics initiative at the University of Michigan. Several learning analytics projects were developed as a result of the initiative, and even though there are no specific details available about whether or not learning analytics played a role in overall administrative development, the initial vision of a campus-wide analytics approach was possible as a result of high-level administrative support. Wintrup (2017) used a macro-level approach to address various aspects of learning analytics integration in higher education, specifically in the United Kingdom. The United Kingdom has suggested a "new national framework that enables the assessment and comparison of teaching quality across higher education (HE) institutions," and one of the three measures they will use is "students' progression and retention" (Wintrup, 2017, p. 87). Administratively, Wintrup noted the importance of students having an overall understanding of what will be observed, and how it will be used, and options for participation (or non-participation) in these observations, as well as understanding how surveilling and labeling students can impact their experiences (p. 99).

Administrators' (technology staff, department directors, etc.) involvement can influence the way institutions use learning analytics across various areas of a univer- 
sity, but their lack of involvement can influence learning analytics as well. For example, in Klein, Lester, Rangwala, and Johri's (2019) study on learning analytics in higher education, they found that the absence of messaging from upper-level administration on the use of learning analytics around the university proved to be a barrier for instructors and advisors. Like the Lonn et al. (2017) work, the Klein et al. study focused on a decentralized higher education institution. However, the university Klein et al. discussed did not have centralized messaging or opportunities related to learning analytics. The frustration those study participants noted is consistent with Macfadyen and Dawson's (2012) findings related to learning analytics and learning management systems. Although the administrators for the institution they studied were involved in initiating the conversation about learning analytics and the university's LMS, the findings were not incorporated into the institution's strategic plan (Macfadyen \& Dawson, 2012), which could also be viewed as a barrier for the use of learning analytics because others across the institution might get the impression that learning analytics is not a priority for the university.

\subsubsection{Classroom-Level Use of Learning Analytics}

Learning management systems (LMSs) sometimes provide myriad ways for instructors to access learning analytics for instructional purposes. This data can be used to both deliver and evaluate instruction. Learning analytics can be used for both modalities of instruction - whether asynchronous/synchronous online or face-toface (Martin \& Ndoye, 2016). For example, Juhaňák, Zounek, and Rohlíková (2019) conducted a study on the use of analytics for examining students' patterns when taking quizzes. Learning analytics, more specifically social network analysis, made it possible for Xie, Yu, and Bradshaw (2014) to explore students' participation patterns in an online course when they were assigned the role of moderator. Similarly, Kim, Yoon, Jo, and Branch (2018) investigated learning analytics as it related to self-regulated learning in asynchronous online courses. Learning analytics allowed instructors to explore elements such as the content that students accessed as well as the amount of time spent on content (Kim et al., 2018). Iglesias-Pradas, Ruiz-deAzcárate, and Agudo-Peregrina (2015) used learning analytics to understand graduate students' competencies related to teamwork and commitment in an online program.

Learning analytics also makes it possible to support students' self-regulated learning by offering student dashboards (Roberts et al., 2016). A unique characteristic of a student dashboard is that it can potentially leverage data at all three levels from providing information to students on how they compare to other students within a university system (macro), to how they are performing across their home institution (meso), to how they are performing within a specific course (micro) (Shum, 2012). At the meso level, like the micro level, the student data that is being used is typically captured through the learning management system interactions. The LMS has the ability to not only organize and deliver the course content, but also 
track and monitor student interaction and behavior patterns (Moore, 2019). There are thousands of different datapoints being collected within the LMS, and dashboards are a visually effective way to display that data. More importantly a dashboard allows for the data to be displayed in a way that can be informative and helpful, not only for students but also for instructors and administrators. As Pardo and Siemens (2014) discuss, these dashboards can give students a real-time analysis of their progress and allow them to take control over their own learning. Since the dashboard is working in real-time, it can also provide on-demand feedback and progress. For instance, a student can visually tell how much of a specific unit module they have completed, what is remaining to be completed and potentially receive automated feedback on assignments. An example of the use of student dashboards at the micro and meso levels can be found in the Course Signals study conducted at Purdue University (Arnold \& Pistilli, 2012). The Course Signals tool was deployed as an early notification system that would allow an instructor to not only flag a student who might be experiencing academic challenges, but also contact them to offer assistance or remediation. Through the use of this tool, students reported that it was useful and helped them be successful at Purdue, while the instructors felt that it empowered students to improve their academic performance (Arnold \& Pistilli, 2012). While this tool was being specifically delivered and used at the micro and meso level, it could feed up to the macro level and give Purdue useful information to employ for overall evaluation and allocation of resources.

In many studies, learning analytics created opportunities to explore components of courses that may not have been accessible previously. However, there are very few works that address the use of learning analytics across a student's overall experience at an institution.

\subsection{An Interdisciplinary Approach}

The focus on interdisciplinary connections of learning analytics data lends itself, primarily, to undergraduate students. However, using an interdisciplinary approach for learning analytics can also benefit graduate students enrolled in dual degree programs, professional development or continuing education students, and graduate students who take courses outside of their programs or can encourage more cooperation within various programs because, as we noted earlier in this chapter, incorporating various disciplines, departments, and perspectives can be beneficial in analytics application. We offer three key areas as a framework to foster this type of approach: awareness, access, and resources (Fig. 3.1). Each of these areas can assist institutions with developing an interdisciplinary approach to learning analytics for students' overall success. 
Fig. 3.1 Awareness, access, \& resources framework

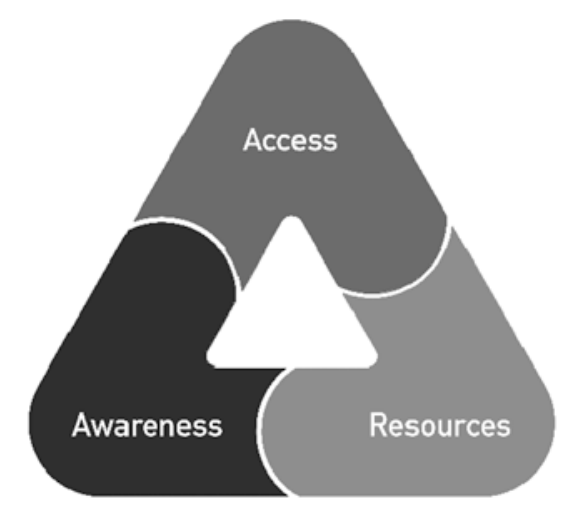

\subsubsection{Awareness - What Is Being Collected and Why}

Awareness of the data collection process involved in analytics brings in the role of the subjects of the data collection efforts - students. One challenge is that the pace at which the area of learning analytics is evolving is faster than the pace at which ethical considerations are deployed to protect the collection and subsequent use of the data (Roberts et al., 2016; Slade \& Prinsloo, 2013; Swenson, 2014). The first issue is that decisions are often being made about data collection without any input from students (Roberts et al., 2016). This is not to say that the institutions have ill intent; instead, they may not have considered how to incorporate student voices into the decision-making process. Not involving students may be a missed opportunity, as students can offer a unique perspective and address potential administrative "blind spots" (Moore, 2019). Also, students have their own ideas about what information they want to share and how it can be used (see, for example, Ifenthaler \& Schumacher, 2016), so their input is crucial to the conversations regarding learning analytics and how or if they participate in these data collection processes. Perhaps one of the key components of the interdisciplinary application of learning analytics data is helping students understand how to access, use, and interpret the data. Students need to know what data is being collected, how administrators and instructors can use the data, and what safeguards exist for protecting their data (Cumbley \& Church, 2013; Rubel \& Jones, 2016). Including students in their own learning analytics conversations gives them the opportunity to view their progress across courses and disciplines. Furthermore, informing students about using learning analytics helps them become more prepared to use this type of data in their respective careers and is one integral step in helping curtail the concern about an overarching analytics narrative. For example, Scholes (2016) discusses the example of "at-risk" or "risky" students (p. 940-941). She points out that "interventions" for these students "could include restriction on the number of courses studied...extra phone calls to encourage engagement," and the like (Scholes, 2016, p. 940). Scholes goes on to say that these methods may work well for some students, but may not work well for others; the grouping of students in this way, through the use of analytics, 
can result in students' harm - perpetuating inequities, demeaning students, etc. These should be areas of alarm for institutions broadly. Including and informing students about analytics use and processes is a crucial component of an interdisciplinary approach. If students are concerned about the narrative the data perpetuates, then they have an opportunity to understand that this is happening and get guidance on how to address any issues they may have with what those analytics narratives present. Institutions must understand that students may have concerns about the sharing of data across units; however, a benefit to eliciting various perspectives through an interdisciplinary approach means that students can get support in areas that may not have been visible initially. Analytics collection processes should explicitly state who can access students' analytics profiles and who cannot. For example, students will need to know that these all-inclusive analytics profiles will not be available to just anyone, and institutions should reiterate the information protections in a number of areas of the university. Instructors, administrators, and other university staff will need this information as well in order to understand what they can and cannot do related to students' analytics data.

\subsubsection{Access - Who Can Get to the Data}

Once the university community is aware of the data being collected and the reasons for collecting it, the next area of focus is who gets access to the data. One of the major challenges related to an interdisciplinary approach to learning analytics, and sometimes learning analytics in general, is access. For example, Klein et al. (2019) noted that in certain contexts, even when learning analytics is used at a university, some areas of that university may have funding to pay for access to analytics data that other areas of the university cannot afford, as it is not uncommon for LMS providers to offer paid options for access to various tools and features. Furthermore, in contexts where funding for analytics access may not be an issue, there is still the challenge of who has permission to access data - an issue that Klein et al. (2019) bring up when discussing academic advisors' permission (or lack thereof) to access analytics data when advising, and one that Shum and Ferguson (2012) note when mentioning the possibility that "analytics could disempower learners" (p.19). Such disparities are not new, but if an institution believes that the overall use of data analytics is beneficial for students, despite various concerns, then applying the data in such different ways means that some students get more benefits than other students. The lines for access are drawn between students in areas on a campus that have robust analytics access and students in areas that do not have such access. By coordinating efforts with the university-level information technology office or an on-campus teaching and learning center, universities can keep track of the various learning analytics tools in use across the institution. This does not mean that units will have to forgo making decisions about analytics that are unique to their areas of the university. However, this practice does mean that there should be institutional messaging as well as an institutional understanding of what analytics data is being 
accessed and how it is being applied. Again, the interdisciplinary approach is designed to integrate the multiple perspectives and experiences of units in order to use that collective knowledge and input for the inclusive application of analytics. Since these enterprise-level offices are often the ones that make decisions about learning management systems, and LMSs are the key point of entry for access to learning analytics tools, it could prove more efficient to have those offices track how various departments and units use campus-wide learning analytics tools. Offices can begin by surveying each unit or department on the campus to get an idea of current learning analytics tools and continue conducting the survey periodically, as learning analytics tools change frequently. Different areas may see their access to analytics as proprietary (see Klein et al., 2019), so they may be reluctant to share information across areas. Therefore, a focus on interdisciplinarity coupled with centralized messaging and information gathering could remove some of the ambiguity around how the tools will be used and who has access to them; the information will become part of a university initiative to focus on improving all students' learning and experiences.

\subsubsection{Resources - Where Is the Data Stored}

Building on the access area, we next focus on the resources, specifically where the data is being stored. Once people are aware of the data being collected and know who has access to this data, they will need to know where this data is stored, not only for retrieval purposes but also to understand the ethical implications involved with data storage (on-site or off-site locations, possibly third-party terms related to privacy, length of time locations hold/have access to data, etc.). The aforementioned extant literature indicates that many analytics efforts are siloed - either in individual areas of a university or in individual classrooms. While this silo approach may be useful for developing security and access protocols, it limits potential information sharing and collaborative opportunities. The individualized approach to learning analytics can hamper interdisciplinary efforts, and that issue can be exacerbated by lack of analytics resources. One example occurs with undergraduates. A student may be taking courses across multiple instructors or departments within the university. If one department has one set of data resources and another has a different system in place, it can prove difficult for the institution (or even the instructors) to track that student's progress and make it difficult to identify students who may be in need of additional support. The colloquial term for this is a student who has "fallen between the cracks"; those cracks are the siloed resources. Some LMSs, for example, may not automatically provide learning analytics dashboards, and even when they do, some instructors may be unclear about how to best access and implement the analytics dashboard data. Once institutions develop a centralized analytics effort through IT or a teaching and learning center, as suggested in access area of this chapter, they can create an online space, internal or external, explaining what analytics features and resources are offered at their institution or through their current LMS. They could also discuss what third parties like LMS organizations and soft- 
ware providers can access and how long they have access to this data. The site itself would function as a resource for learning analytics support around the university.

This area of the framework is particularly important because it does not assume that all instructors will know how to access and apply learning analytics data. The site could also contain tutorials showing the steps for retrieving analytics data through the LMS, as well as information on how the data can be used by instructors. The site should also take an opportunity to address any privacy concerns instructors may have, and this section of the page should be developed in conjunction with the institution's legal team to ensure that the measures and information are in alignment with current higher education legal practices. Furthermore, the site should address how the university plans to use information on how instructors apply analytics data in courses. For example, some instructors, depending on their position with the university (tenure track, tenured, adjunct or casual instructors, etc.), may be concerned about the role their use of learning analytics will play in their overall evaluations. This step creates an opportunity for leveraging shared governance, as institutions with representation from various groups can include those groups in the development of the policies. Even when institutions do not have formalized groups, they can send surveys to instructors, as a needs assessment of sorts, in order to gain their input on how the use of learning analytics impacts them. These surveys could be delivered individually or from units around the university. For example, departments or units can gather information from the instructors in their areas and share that information with IT or the teaching and learning center. Universities should also be clear about who will use analytics data: these will be the people and units that require additional training and support related to the collection and use of learning analytics information. One major challenge to the implementation of this process, however, is time. The aforementioned tutorials take time to complete, which adds more work to schedules that, in most cases, are already full. However, if universities are going to use analytics, then that comes with the responsibility for the ethical, inclusive collection and use of that data. If institutions want to use analytics data, then they must provide designated time for instructors, students, and administrators who use the data to get the appropriate training, and these opportunities must be incorporated into existing structures, not add another item to an already lengthy list. There are a number of policies, laws, and codes that govern how universities can (and cannot) use information. The potential litigation involved in violating certain policies can result in much lengthier, more expensive processes than working with units to develop designated, incorporated times for data analytics training. In order to truly leverage learning analytics for interdisciplinary purposes, all levels of administrators, instructors, and students must feel included, respected, and protected in the process. 


\subsection{Future Directions}

Each area listed provides a foundation for an interdisciplinary approach to applying learning analytics. Administrators, instructors, and students can work together to understand what information can be accessed, how it will be accessed, and how it will be connected to create an overall profile that administrators, instructors, and students can use to better understand students' learning and higher education experiences across courses and activities. With current and future uses of learning analytics data, it will be important for institutions to take any concerns about information sharing and privacy seriously because if users feel that their concerns are dismissed, then they may be reluctant to use learning analytics tools. Another key component to the overall implementation of an interdisciplinary approach, now and in the future, is having clear guidelines about who can access data. For example, in the Klein et al. (2019) text, advisors were concerned about their lack of access to learning analytics data. This is why the access area of the framework is so important. As the Lonn et al. (2017) text showed, there is a benefit to campuses taking a more centralized approach to learning analytics. Addressing issues related to who can access the data and for what purposes is integral to the successful application of an interdisciplinary approach to learning analytics. However, universities will have to be very clear about how they will use this centralized data so that instructors, administrators, and others can know what (if anything) the centralized data will mean for tenure, promotion, job security, and other areas.

Addressing analytics adoption with a framework that supports interdisciplinarity could also provide an overall benefit of helping students develop technologically. If there are students who still do not understand the power of a digital imprint, and the narratives analytics create are a form of digital imprint, then analytics discussions can bring these issues to the fore, along with larger discussions about the ethics of these panoptic practices. If universities want to create more technologically savvy and responsible students, then helping students understand their own on-campus digital imprints via learning analytics is one of the many ways to work toward that goal. Although the discussion of analytics is not a substitute for larger discussions about digital literacy, it is one of many entry points for that conversation. Institutions can include this information as a part of orientation for any online or face-to-face students who are new to the university. The information can also be reiterated in courses, particularly courses designed to teach students about study skills and other aspects of the university. Having an all-inclusive approach to data, and introducing this to students early on, can be crucial to their success at an institution and can help them explore areas where they think they need more support or where they would like to improve. Because the interdisciplinary information will be combined in a university profile, students can access this information across their various courses, as well as have a say in how this information is used. 


\subsection{Conclusion}

In this chapter, we began with an overview of learning analytics and the use of big data in institutions of higher education. We next provided a discussion of the ways that data can be used both at the administrative level and in the classroom. Using this as the background, we offered three key areas as a framework that institutions should use to develop an interdisciplinary approach to learning analytics. Big data and learning analytics can be leveraged together to improve student outcomes within higher education institutions (Moore, 2019). This synergy can be found with the development of prediction models for retention (de Freitas et al., 2015) and with course-level data providing individualized student feedback and scaffolding (Arnold $\&$ Pistilli, 2012). Through the three areas of awareness, access, and resources, we hope to provide information that will be useful to higher education institutions as they consider how to build the infrastructure for their learning analytics apparatus. The potential impacts and benefits for students have been identified, but it is up to institutions to determine what their specific needs and goals are and how they can develop a sustainable and institution-specific system. At the heart of these discussions are more comprehensive connections between administrators, instructors, advisors, and students. Figuring out ways to incorporate students in the decisionmaking process can only help to make the system more responsive and effective toward the overall goal of improving student success within the institution.

\section{References}

Aguilar, S. J. (2018). Learning analytics: At the nexus of big data, digital innovation, and social justice in education. TechTrends, 62(1), 37-45. https://doi.org/10.1007/s11528-017-0226-9

Arnold, K. E., \& Pistilli, M. D. (2012). Course signals at Purdue: Using learning analytics to increase student success. Proceedings of the 2 nd international conference on learning analytics and knowledge - LAK '12, pp. 267-270. https://doi.org/10.1145/2330601.2330666.

Asif, R., Merceron, A., Ali, S. A., \& Haider, N. G. (2017). Analyzing undergraduate students' performance using educational data mining. Computers \& Education, 113, 177-194. https:// doi.org/10.1016/j.compedu.2017.05.007

Bronnimann, J., West, D., Huijser, H., \& Heath, D. (2018). Applying learning analytics to the scholarship of teaching and learning. Innovative Higher Education, 43(5), 353-367. https:// doi.org/10.1007/s10755-018-9431-5

Corrin, L., Kennedy, G., French, S., Shum, S. B., Kitto, K., Pardo, A., ... Colvin, C. (2019). The ethics of learning analytics in Australian higher education. A discussion paper. Retrieved from https://melbourne-cshe.unimelb.edu.au/_data/assets/pdf_file/0004/3035047/LA_Ethics_ Discussion_Paper.pdf

Cumbley, R., \& Church, P. (2013). Is "Big Data" creepy? Computer Law \& Security Review, 29(5), 601-609. https://doi.org/10.1016/j.clsr.2013.07.007

Daniel, B. (2015). Big Data and analytics in higher education: Opportunities and challenges. British Journal of Educational Technology, 46(5), 904-920. https://doi.org/10.1111/bjet.12230

de Freitas, S., Gibson, D., Du Plessis, C., Halloran, P., Williams, E., Ambrose, M., et al. (2015). Foundations of dynamic learning analytics: Using university student data to increase retention. 
British Journal of Educational Technology, 46(6), 1175-1188. https://doi.org/10.1111/ bjet. 12212

Ferguson, R., Clow, D., Griffiths, D., \& Brasher, A. (2019). Moving forward with learning analytics: Expert views. Journal of Learning Analytics, 6(3), 43-59. https://doi.org/10.18608/ jla.2019.63.8

Gray, C. C., \& Perkins, D. (2019). Utilizing early engagement and machine learning to predict student outcomes. Computers \& Education, 131, 22-32. https://doi.org/10.1016/j. compedu.2018.12.006

Ifenthaler, D., \& Schumacher, C. (2016). Student perceptions of privacy principles for learning analytics. Educational Technology Research and Development, 64(5), 923-938. https://doi. org/10.1007/s11423-016-9477-y

Iglesias-Pradas, S., Ruiz-de-Azcárate, C., \& Agudo-Peregrina, Á. F. (2015). Assessing the suitability of student interactions from Moodle data logs as predictors of cross-curricular competencies. Computers in Human Behavior, 47, 81-89. https://doi.org/10.1016/j.chb.2014.09.065

Juhaňák, L., Zounek, J., \& Rohlíková, L. (2019). Using process mining to analyze students' quiztaking behavior patterns in a learning management system. Computers in Human Behavior, 92, 496-506. https://doi.org/10.1016/j.chb.2017.12.015

Kim, D., Yoon, M., Jo, I.-H., \& Branch, R. M. (2018). Learning analytics to support self-regulated learning in asynchronous online courses: A case study at a women's university in South Korea. Computers \& Education, 127, 233-251. https://doi.org/10.1016/j.compedu.2018.08.023

Klein, C., Lester, J., Rangwala, H., \& Johri, A. (2019). Learning analytics tools in higher education: Adoption at the intersection of institutional commitment and individual action. The Review of Higher Education, 42(2), 565-593. https://doi.org/10.1353/rhe.2019.0007

Long, P., \& Siemens, G. (2011). Penetrating the Fod: Analytics in learning and education. Educause Review, 46(5), 31-40. Retrieved from https://er.educause.edu/articles/2011/9/ penetrating-the-fog-analytics-in-learning-and-education

Lonn, S., McKay, T. A., \& Teasley, S. D. (2017). Cultivating institutional capacities for learning analytics. New Directions for Higher Education, 2017(179), 53-63. https://doi.org/10.1002/ he. 20243

Macfadyen, L. P., \& Dawson, S. (2012). Numbers are not enough. Why e-learning analytics failed to inform an institutional strategic plan. Educational Technology \& Society, 15(3), 149-163.

Martin, F., \& Ndoye, A. (2016). Using learning analytics to assess student learning in online courses. Journal of University Teaching \& Learning Practice, 13(3), 1-20. https://doi. org/10.1177/0047239516656369

Moore, R. L. (2016). Interacting at a distance: Creating engagement in online learning environments. In L. Kyei-Blankson, J. Blankson, E. Ntuli, \& C. Agyeman (Eds.), Handbook of research on strategic management of interaction, presence, and participation in online courses (pp. 401-425). https://doi.org/10.4018/978-1-4666-9582-5.ch016

Moore, R. L. (2019). The role of data analytics in education: Possibilities and limitations. In B. Khan, J. Corbeil, \& M. Corbeil (Eds.), Responsible analytics and data mining in education: Global perspectives on quality, support, and decision making (pp. 101-118). New York: Routledge.

Pardo, A., \& Siemens, G. (2014). Ethical and privacy principles for learning analytics. British Journal of Educational Technology, 45(3), 438-450. https://doi.org/10.1111/bjet.12152

Picciano, A. G. (2012). The evolution of big data and learning analytics in American higher education. Journal of Asynchronous Learning Networks, 16(3), 9-20. https://doi.org/10.24059/olj. v16i3.267

Prinsloo, P., \& Slade, S. (2018). Mapping responsible learning analytics: A critical proposal. In B. Khan, J. R. Corbeil, \& M. E. Corbeil (Eds.), Responsible analytics and data mining in education: Global perspectives on quality, support, and decision making (pp. 63-79). https://doi. org/10.4324/9780203728703-5

Rhoten, D., \& Pfirman, S. (2007). Women in interdisciplinary science: Exploring preferences and consequences. Research Policy, 36, 56-75. https://doi.org/10.1016/j.respol.2006.08.001 
Roberts, L. D., Howell, J. A., Seaman, K., \& Gibson, D. C. (2016). Student attitudes toward learning analytics in higher education: "The Fitbit version of the learning world". Frontiers in Psychology, 7, 1-11. https://doi.org/10.3389/fpsyg.2016.01959

Rubel, A., \& Jones, K. M. L. (2016). Student privacy in learning analytics: An information ethics perspective. The Information Society, 32(2), 143-159. https://doi.org/10.1080/01972243.2016 .1130502

Scheffel, M., Tsai, Y.S., Gašević, D., \& Drachsler, H. (2019). Policy matters: Expert recommendations for learning analytics policy. European Conference on Technology Enhanced Learning, p.510-524. Retrieved from https://link.springer.com/chapter/10.1007/978-3-030-29736-7_38

Scholes, V. (2016). The ethics of using learning analytics to categorize students on risk. Educational Technology Research and Development, 64(5), 939-955. https://doi.org/10.1007/ s11423-016-9458-1

Shorfuzzaman, M., Hossain, M. S., Nazir, A., Muhammad, G., \& Alamri, A. (2019). Harnessing the power of big data analytics in the cloud to support learning analytics in mobile learning environment. Computers in Human Behavior, 92, 578-588. https://doi.org/10.1016/j. chb.2018.07.002

Shum, S. B. (2012). Learning analytics. Retrieved from https://iite.unesco.org/pics/publications/ en/files/3214711.pdf

Shum, S. B., \& Ferguson, R. (2012). Social learning analytics. Journal of Educational Technology \& Society, 15(3), 3-26. Retrieved from https://www.jstor.org/stable/10.2307/jeductechsoci.15.3.3

Slade, S., \& Prinsloo, P. (2013). Learning analytics: Ethical issues and dilemmas. American Behavioral Scientist, 57(10), 1510-1529. https://doi.org/10.1177/0002764213479366

Swenson, J. (2014). Establishing an ethical literacy for learning analytics. Proceedings of the fourth international conference on learning analytics and knowledge - LAK '14, pp. 246-250. https://doi.org/10.1145/2567574.2567613.

Villano, R., Harrison, S., Lynch, G., \& Chen, G. (2018). Linking early alert systems and student retention: A survival analysis approach. Higher Education, 76(5), 903-920. https://doi. org/10.1007/s10734-018-0249-y

Voithofer, R., \& Ham, M. (2018). Ethical issues and potential unintended consequences of databased decision making. In B. Khan, J. R. Corbeil, \& M. E. Corbeil (Eds.), Responsible analytics and data mining in education: Global perspectives on quality, support, and decision making (pp. 213-228). https://doi.org/10.4324/9780203728703-16

Wintrup, J. (2017). Higher education's panopticon? Learning analytics, ethics, and student engagement. Higher Education Policy, 30(1), 87-103. https://doi.org/10.1057/s41307-016-0030-8

Xie, K., Yu, C., \& Bradshaw, A. C. (2014). Impacts of role assignment and participation in asynchronous discussions in college-level online classes. The Internet and Higher Education, 20, 10-19. https://doi.org/10.1016/j.iheduc.2013.09.003

Yang, L. (2013). Big Data analytics: What's the big deal? Retrieved September 22, 2017, from http://knowledge.ckgsb.edu.cn/2013/12/30/technology/big-data-analytics-whats-big-deal/ 